\title{
ESTUDO DA ASSISTÊNCIA INTEGRAL À CRIANÇA E AO ADOLESCENTE ATRAVÉS DA PESQUISA QUALITATIVA*
}

\author{
Semiramis Melani Melo Rocha** \\ Regina Aparecida Garcia de Lima** \\ Carmen Gracinda Silvan Scochi** \\ Dulce Maria Silva Vendrúsculo** \\ Débora Falleiros Mello**
}

ROCHA, S.M.M.; LIMA, R.A.G.de; SCOCHI, C.G.S.;VENDRÚSCULO, D.M.S.; MELLO, D.F. Estudo da assistência integral à criança e ao adolescente através da pesquisa qualitativa. Rev.latino-am.enfermagem, Ribeirão Preto, v. 6, n. 5, p. 5-15, dezembro 1998.

Este artigo tem o objetivo de apresentar o referencial teórico e a metodologia que embasa a pesquisa qualitativa desenvolvida pelo Grupo de Estudos e Pesquisa em Saúde da Criança e do Adolescente da Escola de Enfermagem de Ribeirão Preto da Universidade de São Paulo, tendo por objeto de investigação a assistência integral à saúde da criança e do adolescente. Inicialmente, as autoras apresentam o setor saúde na sociedade brasileira atual no qual desenvolvem-se as ações de saúde, passando à apresentação do Grupo de Estudos em questão. Desenvolvem, a seguir, o referencial teórico metodológico, definindo as categorias analíticas - política e politicas sociais, organização tecnológica do trabalho, serviços de saúde, criança e família. Finalizando, apresentam uma síntese dos resultados de algumas investigações concluídas nos três últimos anos (1995 a 1997).

UNITERMOS: assistência integral à criança e ao adolescente, enfermagem pediátrica, enfermagem neonatal

\section{INTRODUÇÃO}

As investigações sobre assistência à saúde da criança e do adolescente têm apontado dois polos nos quais a sociedade centraliza os cuidados à saúde: o hospital e os serviços na comunidade.

A partir da Segunda Grande Guerra, de 1946 até 1960, o hospital foi considerado a peça central do sistema, concentrando o papel de desenvolver a pesquisa, o ensino e as inovações no cuidado à saúde, podendo afirmar-se que nesse período a assistência caracterizava-se por um hospitalocentrismo, sustentado por um modelo médico assistencial privatista, privilegiando a prática médica curativa individual, assistencialista e especializada financiada pela Previdência Social.

Na década de 1970, diante das precárias condições de assistência à saúde da população não coberta pelos serviços do Instituto Nacional de Previdência Social (INPS), surgiram as propostas de extensão de cobertura, e dentre elas o Programa Materno Infantil, alicerçado no movimento internacional de promoção à saúde e reorganização de serviços voltando-os para os cuidados primários. Em suas proposições gerais, apregoa o atendimento sistematizado, agendado, multiprofissional, com delegação de funções, trabalho em equipe, em um sistema de serviços regionalizados e hierarquizados em escala de complexidade crescente com ênfase na atenção primária. A importância numérica do grupo materno infantil, cerca de $70 \%$ da população, naquela década, justificaria o investimento, mas a escassez de recursos levou a utilização da estratégia de categorização da população em grupos de risco, que pode ser definida como uma política social e de saúde para a intervenção racionalizadora baseada em informações válidas sobre custos, recursos, riscos de doenças e efetividade das diversas atividades em diferentes locais. Na prática, os grupos passam a ser caracterizados por condições sócioeconômicas, educação, habitação, áreas periféricas de centros urbanos, áreas rurais, entre outras. Tenta-se assegurar um mínimo de cuidados para todos, distribuindo os limitados recursos para aqueles que mais necessitam (MARQUES, s/d).

\footnotetext{
* Projeto Integrado financiado pela FAPESP e CNPq

**Docentes do Departamento de Enfermagem Materno-Infantil e Saúde Pública da Escola de Enfermagem de Ribeirão Preto da Universidade de São Paulo
} 
Nos anos 80, o modelo médico-assistencial privatista foi substituído por um projeto que incorporou o ideal da chamada Reforma Sanitária Brasileira, consolidando-se na Constituição de 1988 o entendimento da saúde como direito social, universal, derivado de uma cidadania plena. As ações e serviços de saúde são caracterizados como de relevância pública, com a criação de um Sistema Único de Saúde organizado segundo as diretrizes de descentralização, atendimento integral e participação da comunidade. É um período de intensa rediscussão do modelo dicotômico previdenciário, não compatível com as demandas da população. As conquistas sociais na área da saúde criam um arcabouço jurídicolegal, através da Constituição Federal de 1988, Constituições Estaduais, Leis Orgânicas Municipais e posteriormente, as Leis Orgânicas de Saúde 8.080 e 8.142, de 1990, capazes de determinar profundas transformações no modelo de assistência à saúde. Por outro lado, este ideário foi parcialmente derrotado por uma profunda crise política, econômica e social do Estado, facilitando o avanço de propostas neoliberais que na área da saúde traduzemse pela privatização, descentralização e focalização, levando ao que MENDES (1994) chama de "universalização excludente", que garante a incorporação ao sistema público de segmentos mais carentes da população e uma expulsão de camadas mais privilegiadas que podem optar por um serviço supletivo. Na medicina supletiva incorporam-se cooperativas médicas, seguros saúde, medicinas de grupo, planos autogerenciados e modelos administrados por terceiros, que em tese operam sob duas lógicas: sistema de seguro e sistema de prépagamento. Entretanto, na prática, há sobreposição desses sistemas de financiamento, compromentendo a saúde e a qualidade da cobertura oferecida à população.

Consideramos este cenário o conjunto de determinantes sociais, políticos e econômicos nos quais inserem-se as estratégias de assistência integral à saúde da criança e do adolescente. Portanto, nosso objeto de estudo, a assistência integral à saúde da criança e do adolescente, é histórico e leva-nos a utilizar um referencial teórico que, partindo da observação empírica dos fatos, toma o objeto de investigação e o abstrai da realidade analisando o conjunto das determinações que o configuram e o devolve à realidade como um concreto pensado, que o diferencia do anterior por esclarecer suas determinações para além de sua aparência imediata. Esta passagem, do concreto para o abstrato e volta para o concreto, fundamenta-se na dialética hegeliana e marxista. Este trabalho tem como objetivo apresentar o referencial teórico e metodológico deste projeto temático de investigação e uma síntese dos resultados de alguns estudos realizados até o momento. Para situar o leitor, descrevemos inicialmente o Grupo de Estudos em Saúde da Criança e do Adolescente.
GRUPO DE ESTUDOS EM SAÚDE DA CRIANÇA E DO ADOLESCENTE

O Grupo de Estudos em Saúde da Criança e do Adolescente foi criado em março de 1991, no Departamento de Enfermagem Materno-Infantil e Saúde Pública, aglutinando aproximadamente trinta participantes, entre eles pesquisadores, doutorandos, mestrandos e bolsistas vinculados a diversas instituições de ensino e assistência, cujo objeto de estudo é a assistência à saúde da criança, apreendendo-a em suas relações com a família, a comunidade, o setor saúde e em suas necessidades no processo de crescimento e desenvolvimento. Ao longo do tempo, o número de participantes tem oscilado, conforme a conclusão de cursos de pós-graduação, bolsas de aperfeiçoamento e a inclusão de novos participantes.

O objetivo geral do projeto de pesquisa é identificar as necessidades de assistência à criança e ao adolescente, no processo de trabalho em saúde às quais o trabalho de enfermagem responde. É um objetivo amplo e complexo e para operacionalizá-lo, a investigação foi contextualizada e subdividida em objetivos específicos em três áreas: Atenção Primária à Saúde da Criança, Assistência à Criança Hospitalizada e Enfermagem Neonatal.

Pelo fato do Grupo de Estudos estar sediado no município de Ribeirão Preto, muitas das investigações têm seus objetos de estudo contextualizado em nível local e, portanto, torna-se oportuno situá-lo em sua dimensão geográfica e demográfica. Localiza-se na região nordeste do Estado de São Paulo, sendo sede da Diretoria Regional de Saúde - DIR 18. Pelo Censo Demográfico de 1991, possui uma população de 436.122 habitantes, sendo $2,2 \%$ distribuída na zona rural. Quanto às faixas etárias $29,9 \%$ está entre 0 a 14 anos: $1,8 \%$ menores de 1 ano; $11,7 \%$ de 1 a 6 anos e $6,4 \%$ de 7 a 14 anos (FIBGE, 1994).

No ano de 1996 foram notificados 8.624 nascimentos cuja procedência materna era de Ribeirão Preto, 16,7\% deles eram de mães menores de 19 anos. A população de mulheres é aproximadamente $52 \%$ da população geral, $68 \%$ delas em idade fértil (RIBEIRÃO PRETO, 1995).

O município é polo econômico de produção agrícola de cana de açúcar para industrialização, de soja, milho, café, entre outros; o comércio é intenso e diversificado. É considerado um grande centro de referência de assistência à saúde para atenção terciária e de especificidades.

Os resultados das pesquisas realizadas pelos integrantes do Grupo de Estudos em Saúde da Criança e do Adolescente têm sido socializados através de publicações em periódicos nacionais e internacionais, livros, capítulos de livros, jornais e apresentações em eventos científicos nacionais e internacionais, bem como 
difundidos nos serviços de extensão e cursos de graduação, especialização de longa duração e pósgraduação. Além disso, membros do grupo assessoram comissões técnicas, científicas e órgãos deliberativos de serviços de saúde.

Alguns objetivos do projeto foram atingidos com as investigações realizadas no período de 1992 a 1996.

Dando seqüência, em um estudo sobre a assistência integral à saúde da criança no Brasil, ROCHA et al. (1997) consideram que, atualmente, as necessidades de assistência, estendendo-se do período neonatal à adolescência, convergem para a apreensão da criança em sua dimensão biológica, social e em sua subjetividade; o envolvimento dos pais e da família no processo de promoção, prevenção, diagnóstico, terapêutica e reabilitação; a organização do processo de trabalho em equipes multiprofissionais e multidisciplinares; a compreensão das instituições de saúde como espaços de produção de serviços nos quais estabelecem-se relações sociais complexas, tendo o poder como um dos principais determinantes. Com estas quatro temáticas demos continuidade ao projeto integrado agora denominado "A enfermagem profissional e a assistência integral à criança e ao adolescente".

\section{O REFERENCIAL TEÓRICO E METODOLÓGICO}

As ciências sociais, em suas atividades de investigação, fazem uso de categorias analíticas, categorias empíricas e conceitos operacionais. TESTA (1992, p.95) define categoria analítica como

"uma abstração realizada com base no exame de uma realidade - embora um exame parcial, que pode incluir imprecisões $e$ ambigüidades, mas que está fundamentado em experiências concretas - cuja importância é primordial para a investigação, porque não só determina sua orientação geral, como permite sua interpretação correta".

Para o mesmo autor, o conceito operacional é um invento elaborado com fins práticos: manipulações do problema ou substrato sobre o qual se assenta o funcionamento de categorias analíticas. empírica como

MINAYO (1993, p.94) define categoria

"aquela construida com finalidade operacional visando o trabalho de campo (a fase empírica) ou a partir do trabalho de campo. Ela tem a propriedade de conseguir apreender as determinações e as especificidades que se expressam na realidade empírica".

Em nossas investigações utilizamos como ponto de partida algumas categorias analíticas, descritas a seguir, tendo como referência os autores TESTA (1992) e MENDES GONÇALVES (1994), entre outros, podendo, de acordo com os resultados parciais da investigação, serem incluídas outras.

Para TESTA (1992), política é uma atividade realizada por grupos que compõem a sociedade em torno da relação social que constitui o poder, ou seja, política é uma proposta sobre a distribuição do poder nas sociedades.

As políticas sociais ora são vistas como mecanismos de manutenção da força de trabalho, ora como conquista dos trabalhadores, ora como arranjos do bloco no poder ou bloco governante, ora como doação das elites dominantes, ora como instrumento de garantia do aumento da riqueza ou dos direitos do cidadão. Assim, as políticas sociais desenvolvem-se em articulação com a inclusão, a reprodução e a exclusão da mão-de-obra no processo produtivo e com as lutas sociais.

SANTOS (1979) vê a política social como eqüidade ou redução de desequilíbrios, dividindo o bem estar social em vários componentes a partir de carências em áreas de saúde, educação, habitação, trabalho, previdência, nutrição, assistência e recreação. Comenta, ainda, que a função dessas políticas seria a redistribuição de renda e benefícios sociais.

Os serviços de saúde, e particularmente os hospitais, são tomados como unidades de observação e análise, por se constituírem em lugares estruturais de produção de cuidados médicos, onde se reúnem profissionais, saberes, tecnologia e infra-estrutura e onde se configuram relações sociais (CARAPINHEIRO, 1993). Os hospitais têm sido tomados para estudo na assistência à criança como locais que interferem no desenvolvimento infantil, numa perspectiva psicológica, porém, não encontramos trabalhos que os analisem numa abordagem sociológica, problematizando a assistência à criança hospitalizada.

A tecnologia é entendida como o conjunto de saberes e equipamentos, em suas relações no processo de trabalho, socialmente determinados que articulam seus agentes à dinâmica da produção e reprodução social através do trabalho (MENDES GONÇALVES, 1994). Portanto, a organização tecnológica do trabalho é entendida como o processo de trabalho constituído por seus instrumentos, agentes e atividade dirigida a uma finalidade.

As crianças são seres em crescimento e 
desenvolvimento, com necessidades específicas em cada fase, pertencendo a diferentes classes sociais, apresentando desigualdades não apenas biológicas, ditadas pelas etapas de amadurecimento de suas funções orgânicas, mas socialmente determinadas, havendo uma relação diretamente proporcional entre suas vulnerabilidades, riscos de adoecer, danos e suas condições de existência e qualidade de vida.

Por definição, família e parentesco são duas realidades complementares que devem ser compreendidas em relação uma com a outra. Sistema de parentesco ou de filiação e sistema de aliança existem em todas as sociedades e devem estar de acordo de um modo ou de outro. Essas duas lógicas de organização são interdependentes e suas relações são um dos fundamentos principais do sistema social global de uma sociedade. Não obstante, para se compreender as sociedades modernas, sociólogos, etnólogos e antropólogos, procuram apreender o parentesco como um fenômeno social e não biológico. Ao estudarem o parentesco, eles estudam um sistema social que tem relações com os fenômenos biológicos, mas é a maneira pela qual a sociedade trata o fenômeno biológico que interessa a eles (MENDRAS, 1975).

Em nossas investigações, a família significa um universo regulado por regras sociais correspondendo, portanto, a uma construção que apresenta variabilidade, conforme o contexto cultural onde se desenvolve (SARTI, 1995).

Além de categorias que buscam a dimensão qualitativa em estudo, utilizamos também estatísticas de saúde, que consistem em dados relativos a nascimentos, óbitos e perdas fetais, população, doenças e serviços, que trabalhados sob a forma de coeficientes e indicadores, podem se constituir na base para a elaboração de diagnósticos em saúde coletiva (LAURENTI, 1987).

É necessário realizar diagnósticos comunitários de saúde infantil para identificar as principais doenças e agravos à saúde, medir sua magnitude, instrumentalizar práticas e avaliar a utilização dos serviços existentes. Tais diagnósticos fornecem o pano de fundo para as pesquisas qualitativas, que buscam esclarecer a intencionalidade, as determinações sociais, o sentido e o significado que os números indicam mas não revelam.

A complementação de fontes de coletas de dados empíricos é benéfica, pois possibilita abarcar de forma mais ampla a realidade em questão. Uma técnica qualitativa pode coexistir com uma quantitativa, pois elas não devem ser consideradas opostas ou mutuamente excludentes. Uma pesquisa quantitativa pode direcionar o investigador à escolha de um problema particular a ser analisado em toda sua complexidade, através de métodos e técnicas qualitativas e vice-versa (MINAYO, 1993).

A criança, a família e as instituições de saúde poderão ser tomadas como unidades para estudos de caso individual, na forma de história de vida e de comunidade ou organização. Adaptado da tradição médica, o estudo de caso tornou-se uma das principais modalidades de análise das ciências sociais; geralmente tem um propósito duplo pois, se por um lado, tenta chegar a uma compreensão abrangente do grupo de estudo, ao mesmo tempo também, tenta desenvolver declarações teóricas mais gerais sobre regularidades do processo e estruturas sociais (BECKER, 1994).

Definido o campo de investigação como as políticas e modalidades de assistência à saúde da criança e do adolescente na sociedade brasileira contemporânea, elege-se, como estratégias de investigação a coleta de dados nas seguintes fontes:

- documentos oficiais de órgãos federais, estaduais, municipais, instituições de ensino e saúde;

- estatísticas de serviços de assistência à infância ambulatoriais, hospitalares, de proteção ao menor;

- sistemas de informação oficiais e institucionais públicos municipais, estaduais e não governamentais;

- levantamento de prontuários de pacientes/clientes nas instituições;

- observação em suas diferentes modalidades;

- entrevistas em suas diferentes modalidades.

A observação possibilita descrever e situar os fatos únicos e os cotidianos construindo cadeias de significados. Pode assumir várias formas (participante ou não) e é ao mesmo tempo a mais antiga e a mais moderna das técnicas de pesquisa. Ela é necessária porque, geralmente, as pessoas têm mais dificuldades de descrever suas ações através da fala, sendo assim, esta técnica propicia captar nuances complexas não captáveis pela linguagem (WEICK, 1968).

A técnica de observação também é útil para "descobrir" aspectos novos de um problema, para tanto, precisa ser antes de tudo controlada e sistemática. Assim, um planejamento cuidadoso do trabalho e uma preparação rigorosa do observador são fundamentais e imprescindíveis. Segundo PATTON (1980) para realizar as observações é preciso preparo material, físico, intelectual e psicológico. Acrescenta ainda, que o observador precisa aprender a fazer os registros descritivos, saber separar os detalhes relevantes dos triviais, aprender a fazer anotações organizadas e utilizar métodos rigorosos para avaliar suas observações. $\mathrm{O}$ conteúdo das observações deve envolver uma parte descritiva e uma parte reflexiva, buscando manter sempre uma perspectiva de totalidade.

A observação sistemática de crianças nos diversos momentos e situações de trabalho possibilitará "retratar" as necessidades, a finalidade, os instrumentos e os ajustes envolvidos neste processo. Pode ser documentada através de registros escritos ou por filme e videotape. Segundo DELGADO (1964), como 
registradores, estas duas últimas técnicas são realmente os meios ideais de armazenar informações, pois os registros cinematográficos são permanentes e objetivos, podendo obter-se seqüências longas e contínuas de fatos relevantes.

As pesquisas para as quais o filme cinematográfico e o videotape são particularmente adequados reúnem-se em cinco grupos: quando a ação ocorre tão rapidamente que é impossível registrar todos os elementos necessários por qualquer outro meio; quando a ação é tão complexa que a atenção fixa-se em determinados componentes a expensas dos demais; quando as mudanças no comportamento são tão sutis que se torna difícil uma delineação satisfatória entre um ato e outro; quando as mudanças seqüenciais de comportamentos complexos estão sendo consideradas e quando é necessário medir com precisão parâmetros específicos de certos eventos comportamentais breves e complexos (HUTT \& HUTT, 1974).

Estes recursos são passíveis de operacionalização na observação de recém-nascidos, crianças, adolescentes, famílias e serviços de saúde, a depender das investigações.

A entrevista, ao lado da observação, representa um dos instrumentos básicos para a coleta de dados. Ao invés de procurar "retratar" sistematicamente todo o processo sob investigação, na entrevista selecionam-se aspectos dele, relevantes para o esclarecimento das questões centrais do estudo.

Há diferentes formas de entrevista. LÜDKE \& ANDRÉ (1986) fazem a seguinte tipologia:

1. Entrevista não-estruturada ou não padronizada, quando não há imposição de uma ordem rígida de questões; o entrevistado discorre sobre o tema proposto e a medida em que houver clima de estímulo e de aceitação mútua, as informações fluirão.

2. Entrevista padronizada ou estruturada é aquela em que o entrevistador tem que seguir muito de perto um roteiro de perguntas feitas a todos os entrevistados de maneira idêntica e na mesma ordem; é utilizada quando se visa à obtenção de resultados uniformes entre os entrevistados, permitindo comparação imediata, em geral mediante tratamentos estatísticos.

3. Entrevista semi-estruturada, desenvolve-se a partir de um esquema básico, porém flexível, pois permite que o entrevistador faça as necessárias adaptações.

A entrevista pressupõe o caráter de interação; permite o tratamento de assuntos de natureza estritamente pessoal e íntima, assim como temas de natureza complexa e de escolhas nitidamente individuais. Pode, também, permitir o aprofundamento de pontos levantados em outras técnicas de coleta e atingir informantes que não poderiam ser atingidos por outros meios de investigação.

Há basicamente duas formas de registro e ambas carregam pontos positivos e negativos. São elas a gravação direta e a anotação durante a entrevista. A gravação tem a vantagem de registrar todas as expressões orais mas deixa à margem as expressões faciais, os gestos, as mudanças de postura além de poder ser um fator constrangedor. Outra dificuldade é a transcrição, sendo essa uma operação que envolve muito trabalho e tempo do pesquisador. Quanto ao registro feito através de notas durante a entrevista, também deixará de cobrir muitas coisas ditas, mas em compensação, as notas já representam um trabalho inicial de seleção e interpretação das informações emitidas.

\section{SÍNTESE DOS RESULTADOS ALCANÇADOS}

Nesta síntese apresentamos os resultados de alguns trabalhos divulgados nos três últimos anos, isto é, entre 1995 e 1997.

\section{Atenção primária à saúde da criança}

SANT'ANNA (1995) estudou o Programa Integrado de Suplementação Alimentar, no município de Ribeirão Preto, com o objetivo de analisar as relações dos agentes no processo de trabalho com a clientela, dentro das ações de promoção nutricional propostas. Concluiu que o programa apresentava uma discrepância entre suas premissas, objetivos e sua operacionalização. Argumentou que a suplementação alimentar tem por finalidade o controle da desnutrição, o acompanhamento do crescimento e desenvolvimento, a promoção em saúde, atraindo a mãe para a unidade básica, mantendo a criança sob controle do setor saúde. Em Ribeirão Preto, em linhas gerais, o Programa caracteriza-se por uma ação reduzida, limitada à entrega do suplemento alimentar; as relações com a clientela estão comprometidas; os profissionais auxiliares percebem esta ação como um ônus que o setor saúde carrega; o atendimento é tenso e longe de tornarse terapêutico. A assistência à criança fica desviada para a necessidade de controle rigoroso dos tíquetes. Apesar das limitações, o Programa beneficia parcela considerável da população, pessoas, cuja cidadania deve ser restaurada. Para a autora, a unidade de saúde deve monitorar a saúde da comunidade onde se insere, realizar a vigilância em saúde, superar o modelo de assistência atual, limitado a atender as queixas da demanda espontânea.

MELLO \& FERRIANI (1996) realizaram estudo exploratório das opiniões de mães sobre a saúde de crianças menores de 5 anos, relatando episódios de doenças, seus sinais e sintomas e cuidados executados, bem como critérios de inclusão-exclusão do Programa 
de Suplementação Alimentar e aspectos da utilização da atividade de vacinação em unidade básica de saúde. A alimentação foi mencionada como a maior preocupação que as mães têm no cuidado da criança. Os aspectos levantados pelas mães trazem subsídios para a reflexão sobre a atenção à criança na rede básica de saúde, em Ribeirão Preto.

CANO et al. (1996) realizaram levantamento das instituições que prestam assistência aos adolescentes no município de Ribeirão Preto, visitando trinta e cinco estabelecimentos, entre governamentais, filantrópicos e religiosos. Foram excluídos os particulares destinados à camada social de maior poder aquisitivo. As instituições foram classificadas inicialmente em dois setores Educação e Saúde. A seguir, foram agrupadas em: esporte, lazer e arte; adestramento para o mercado de trabalho; cursos profissionalizantes; atividades para crianças e adolescentes provindos de família de baixa renda; proteção e guarda de crianças e adolescentes; assistência ao adolescente dependente de drogas. Finalizando, as autoras fazem uma análise das atividades desenvolvidas, apontando os avanços e as necessidades ainda não resolvidas.

\section{Assistência à criança hospitalizada}

A investigação sobre o ensino das técnicas de enfermagem relacionadas a assistência a criança hospitalizada demonstrou que tem havido transformações, mas elas continuam a ser consideradas como um importante instrumento de trabalho da enfermagem. $\mathrm{O}$ enfoque está predominantemente voltado para as questões de abordagem da criança; os conteúdos e procedimentos são ensinados de acordo com as oportunidades oferecidas pelos campos de estágio. Os resultados indicam uma fase de transição, estando em construção um novo conhecimento em enfermagem pediátrica (COLLET, 1995; COLLET \& ROCHA, 1996).

LIMA (1995), após estudar a situação do leito hospitalar para crianças em Ribeirão Preto/SP (LIMA et al., 1994) descreveu e analisou o processo de trabalho em saúde na assistência à criança com câncer, fundamentando-se no Modelo de Organização Tecnológica do Trabalho, apresentando as principais modificações que vêm ocorrendo. Com a equipe multiprofissional atuando, o psicólogo, o nutricionista, o assistente social, entre outros, introduzem outras ciências, além do modelo clínico centrado na fisiopatologia, que respondem diferentemente aos problemas que surgem, instalando uma nova relação entre os elementos da equipe. $\mathrm{O}$ ambiente hospitalar tornou-se mais informal e descontraído com a presença da mãe. A enfermeira já não se restringe aos aspectos técnicos da assistência, sintetizando a compreensão de uma abordagem que inclui o diagnóstico, a terapêutica, a afetividade, a emoção, o lazer, a recreação e a comunicação com os familiares.

Com o objetivo de identificar as necessidades atuais da criança na atenção à criança hospitalizada, utilizando o mesmo referencial teórico-metodológico, LIMA (1996) descreveu o cotidiano desta assistência a partir de três estruturas: a organização da assistência (o espaço físico, os agentes e o trabalho), o corpo e as emoções (dor e prazer, dependência e autonomia) e as relações sociais (privação e vínculo, relações de poder). Assinala que a criança hospitalizada tem outros carecimentos para além daqueles relacionados ao corpo biológico, sendo que o processo de trabalho conduzido pela medicina clínica pode incorporar estes carecimentos, ampliando-se.

O estudo sobre a participação dos pais na assistência à criança hospitalizada faz uma reflexão sobre os principais benefícios e obstáculos nas relações entre a equipe multiprofissional e a família. Sugere novos estudos sobre: as relações que se estabelecem entre a enfermagem e a família; as diferenças entre alojamentos conjuntos pediátricos em hospitais públicos e privados; 0 preparo de profissionais de saúde para atuar com mais segurança em alojamentos conjuntos, uma vez que a presença e participação dos pais durante a hospitalização de crianças tem criado situações novas e complexas (IMORI et al. 1995).

Dando continuidade a esta temática, LIMA et al. (1997) analisaram a participação dos pais no processo de hospitalização de seus filhos utilizando, também, como referencial teórico-metodológico o Modelo de Organização Tecnológica do Trabalho. A partir da conformação do processo de trabalho, as autoras assinalam que trazer a mãe para a enfermaria não é uma questão simples pois implica na reorganização do trabalho em nível teórico e prático. Finalizam indicando que conceitos como cooperação e parceria estão sendo construídos, entretanto, compartilhar saberes, poderes e espaços também não se constitui ato simples, decorrente da adesão a um discurso, implica sim em mudanças de valores e atitudes para ambos, pais e profissionais.

O controle e o alívio da dor na assistência à criança com câncer tem sido objeto de preocupação da enfermagem na busca de intervenções que possam minimizar, evitar problemas de ordem física e emocional na criança hospitalizada. TORRITESI \& VENDRÚSCULO (1997), descreveram alguns modelos de avaliação e de controle da dor, apresentando a adaptação do modelo de escala visual de faces de Mac Grath et al. (1996), como instrumento que pode ser utilizado na assistência de enfermagem à criança com câncer.

A utilização da arte como instrumento terapêutico na assistência à criança hospitalizada foi implantada na 
Clínica Pediátrica do Hospital das Clínicas de Ribeirão Preto, sendo relatada por FRANÇANI et al. (1996). Utilizando aspectos do "Teatro Clown" e baseado no trabalho dos "Doutores da Alegria", um grupo de alunas de enfermagem, orientado por docente-pesquisador envolvido no Projeto Integrado, montou a Companhia do Riso, que procura resgatar o riso da criança hospitalizada, através de atividades divertidas como 'injeção de alegria', 'extração de mau-humor' e 'transplante de nariz vermelho'.

\section{Enfermagem neonatal}

Em Enfermagem Neonatal, SCOCHI et al. (1996b) descreveram a evolução da assistência ao recémnascido em diferentes momentos históricos. Através da revisão de referências da área de saúde e social, as autoras apreenderam as transformações ocorridas no processo de trabalho, apontando a transposição da visão mística para a assistência embasada em princípios científicos, a ampliação do objeto de ação para além do corpo biológico, envolvendo o binômio mãe-filho, família e comunidade, bem como o trabalho de uma equipe multiprofissional devido à multidisciplinaridade do conhecimento envolvido na assistência.

$\mathrm{Na}$ assistência hospitalar ao recém-nascido, foi analisada a organização do trabalho em quatro berçários da regional de saúde de Ribeirão Preto, constatando diferenças segundo o porte e complexidade do hospital. A ação está centrada na criança e, nos casos mais complexos, prioriza-se a patologia e a assistência clínica; todavia, há práticas cujo objeto é ampliado para o binômio mãe-filho e familiares. O nível de atenção é resultado de uma complexa combinação dos recursos humanos, materiais e área física. A instituição de maior porte e complexidade apresenta diversidade de agentes, trabalho mais burocratizado e hierarquizado, sistema de informação e tecnologias complexas, procedimentos rotinizados mediados por normas escritas e aparelhos sofisticados (SCOCHI et al., 1997a).

SCOCHI et al. (1996a) verificaram que o alojamento conjunto neonatal não está efetivamente implantado em todos os hospitais-maternidade do município de Ribeirão Preto. O trabalho é rotinizado e fragmentado, predominando, na prática, a assistência clínica com uma filosofia curativa de medicalização dos fenômenos fisiológicos da maternidade. Há deficiências qualitativas e quantitativas do pessoal de enfermagem, não atendendo às recomendações técnicas vigentes; as ações educativas sistematizadas, dirigidas às puérperas, não estão implantadas em todas as instituições e mesmo naquelas existentes, na dinâmica, o trabalho é normativo, com atitudes mecânicas e formais, sem considerar, nas orientações, as características individuais da clientela.
A partir da categorização dos equipamentos disponíveis em berçários ROCHA et al. (1996) analisaram a organização tecnológica da assistência ao recémnascido. Verificaram que os instrumentos são utilizados na manutenção das funções vitais, termorregulação, cardio-respiratória, oxigenação, equilíbrio hidro-eletrolítico e nutrição, na administração de medicamentos e coleta de materiais orgânicos para diagnóstico e terapêutica. A enfermagem participa do preparo, instalação, controle e manutenção desses equipamentos, enquanto que os médicos envolvem-se com a instalação e controle, especialmente em procedimentos mais invasivos. A partir desta constatação, procuram o significado que a tecnologia assume, articulada à interação entre os agentes e às finalidades do processo de trabalho. Concluem com uma reflexão teórica sobre organização do processo de trabalho: a tecnologia deve ser desenvolvida por uma prática cotidiana, na qual o conhecimento conduz à ação para satisfazer as necessidades individuais e sociais, indissoluvelmente materiais e subjetivas, num processo de trabalho que é sempre coletivo, embora dividido técnica e socialmente.

KAMADA \& ROCHA (1997) analisaram as medidas para prevenção de infecções em berçários, concluindo que as mesmas têm que ser tomadas em conjunto, num complexo de atividades, fundamentadas em instalações e estruturas hospitalares adequadas, desempenhadas por uma equipe profissional coesa, onde todos trabalhem com os mesmos objetivos. Tomá-las isoladamente não contribui para o efetivo cumprimento das prescrições.

SILVA et al. (1996) descreveram a experiência de atuar junto a pais de crianças assistidas na Unidade de Terapia Intensiva Neonatal do Hospital das Clínicas de Ribeirão Preto. A visita ao recém-nascido é liberada e os pais, auxiliados por uma equipe multiprofissional, desenvolvem o contato precoce, participam do cuidar da criança sempre que possível e das reuniões coordenadas pela enfermeira e pelo pediatra; há comunicação freqüente entre os profissionais e os familiares; a mãe recebe um treinamento para a alta do filho. Com a incorporação de novas tecnologias houve uma maior satisfação da clientela atendida e maior integração entre pais e profissionais de saúde.

MELLO et al. (1995) verificaram a disponibilidade de leitos/berços para recém-nascidos nos hospitais do município de Ribeirão Preto, encontrando 219 assim distribuídos: 29,7\% em enfermaria única para recémnascidos de baixo e médio risco; $20,1 \%$ em área para neonatos normais e em observação; $14,6 \%$ em enfermaria destinada ao pré-termo ou a termo em cuidado intermediário; $10,5 \%$ em área de alojamento conjunto; $3,6 \%$ para isolamento e $21,5 \%$ para cuidados intensivos. Quanto ao financiamento, $53,4 \%$ dos leitos/berços são 
particulares ou convênios com cooperativas médicas e medicina de grupo e $46,6 \%$ são conveniados com o SUS ou públicos.

Sistemas de informação como a declaração de nascidos vivos e registro civil de nascimento constituemse em objeto de pesquisa de um dos projetos. Assim, SCOCHI et al. (1997b) analisaram o intervalo de tempo entre o nascimento e o registro civil no município de Ribeirão Preto, constatando que a amplitude de variação oscilou entre os registros ocorrendo no mesmo dia do nascimento até em períodos superiores a 10 anos. Dentre os registros, $80,90 \%$ ocorreram dentro do prazo legal, isto é, com até 60 dias após o nascimento; $19,10 \%$ eram registros tardios, pois ocorreram acima desse período e, destes, a maioria $(82,74 \%)$ eram registros atrasados pois não ocorreram no mesmo ano do nascimento, representando $15,80 \%$ do total. Diante da freqüência de registros tardios, as autoras recomendam a implantação de medidas nacionais e locais visando incrementar o registro dentro do prazo legal. Consideram que deva ser gratuito; a população deve ser orientada sobre a sua importância para a criança, ressaltando-se as questões relativas à saúde, educação e cidadania, e para o país, pois instrumentalizam ações econômicas, sociais e sanitárias.

A declaração de nascidos vivos (DN) tem sido apontada como fonte promissora de dados sobre os nascimentos, todavia, merece avaliações sobre a consistência das informações nela contidas. Nesse sentido, MISHIMA et al. (1997) compararam os dados da DN oficial com a DN controle preenchida por auxiliares de pesquisa, mediante dados dos prontuários do neonato $\mathrm{e}$ da mãe e do livro de registros hospitalares, referente aos nascimentos ocorridos no mês de julho de 1996. Verificaram que o fluxo de preenchimento da DN em Ribeirão Preto é heterogêneo, envolvendo desde o pediatra até a escriturária do berçário. As informações foram coincidentes nas duas declarações comparadas em mais de $90 \%$ do total e em metade das instituições. Discordância maior foi encontrada nas informações referentes ao número de filhos tidos e de consultas prénatal, escolaridade materna e nome do pai. Face aos dados encontrados, as autoras sugerem a otimização do uso do cartão da gestante e da criança e da DN, avaliação freqüente do Sistema de Informação sobre Nascimentos (SINASC), treinamento sistemático do pessoal responsável pelo preenchimento da $\mathrm{DN}$ e retorno periódico das informações consolidadas às diversas instâncias do setor de serviços de saúde em níveis local, estadual e federal.

FERRO et al. (1997) fizeram uma avaliação do SINASC implantado no município de Ribeirão Preto, a partir de 1993, verificando que com a sistemática organizada para o controle das informações, houve uma redução acentuada nas proporções de informações ignoradas sobre o endereço materno e o peso do neonato. Com a consolidação do SINASC foi possível conhecer melhor as estatísticas sobre os nascimentos por hospital e área geográfica, fornecendo subsídios para os programas locais na área de saúde da criança, em especial aqueles destinados à busca ativa dos recém-nascidos de alto risco.

ROCHA (1995) em um estudo panorâmico intitulado "A criança na sociedade brasileira: educar, prevenir, cuidar", faz uma retrospectiva histórica do movimento de proteção à maternidade e à infância a partir de 1750. Comenta a situação da criança e do adolescente no Brasil contemporâneo, apresenta dados sobre a criança e a escola e conclui fazendo considerações sobre o redimensionamento atual da assistência de enfermagem.

As investigações projetadas para o próximo biênio têm a finalidade de dar continuidade ao conhecimento já elaborado sobre assistência integral à criança e ao adolescente permitindo avançar na postulação de um quadro teórico que contemple a integração de saberes e ações.

\section{PERSPECTIVAS DE INVESTIGAÇÃO}

O referencial teórico apresentado tem permitido trabalhar em investigações procurando desenvolver o conceito de "assistência integral à criança e ao adolescente" através da observação e análise epistemológica, bem como identificar necessidades de assistência em situações concretas. Para atingir esta finalidade, os projetos em andamento têm os seguintes objetivos:

- identificar as necessidades atuais de assistência à criança hospitalizada;

desenvolver princípios teóricos e práticos para subsidiar a utilização do brincar na assistência à criança hospitalizada;

- caracterizar a presença da mãe e da família na assistência à criança hospitalizada, desenvolvendo propostas de interação com a equipe de saúde;

- estudar o modo de vida da mãe, no que se refere à atenção com a saúde dos filhos e dela própria, articulandoo com as mudanças que ocorrem no campo teórico e prático das políticas de saúde;

- analisar a organização da assistência ao recém-nascido em alojamento conjunto;

- apreender a transformação histórica da assistência à criança e ao adolescente e seus determinantes sociais, econômicos e políticos;

- estudar o seguimento da assistência ao recém-nascido pré-termo e de baixo peso e as relações que se 
estabelecem entre as mães e os serviços de saúde.

Os resultados vêm sendo divulgados na medida em que os objetivos parciais vão sendo atingidos e os caminhos metodológicos são redimensionados conforme discussão com a comunidade de enfermagem e demais profissionais que assistem à criança e ao adolescente.
Outro canal de comunicação com os profissionais tem sido o Curso de Especialização em Enfermagem Pediátrica e Neonatológica e os cursos de mestrado e doutorado da Escola de Enfermagem de Ribeirão Preto. Dessa forma, o conhecimento produzido vai sendo socializado e reconstruído.

\section{QUALITATIVE STUDY ON INTEGRAL CARE TO CHILDREN AND ADOLESCENTS}

This paper presents the theoretical reference and methodology applied by the Group of Study on Children's and Adolescent's Health of the University of São Paulo at Ribeirão Preto College of Nursing, in their qualitative research aiming at the integral assistance to children's and adolescent's health. The authors describe the health sector in current Brazilian society, where the health actions take place, following with the presentation of the Study Group. After that, they develop the theoretical reference and methodology, defining the analytical — politics and social policies, technological organization of work, health services, child and family. To conclude, the authors present an outline of the results of investigations carried out in the last three years (1995 to 1997).

KEY WORDS: integral assistance to children and adolescent, pediatric nursing, neonatal nursing

\section{ESTUDIO DE ASISTENCIA INTEGRAL AL NIÑO Y AL ADOLESCENTE A TRAVÉS DE LA INVESTIGACIÓN CUALITATIVA}

Este artículo tiene como objetivo presentar el referencial teórico y la metodología en la que se fundamenta la investigación cualitativa, desarrollada por el grupo de estudios e investigación del niño y del adolescente de la Escuela de Enfermería de Ribeirão Preto de la Universidad de San Pablo - Brasil; inicialmente las autorasa presentan al sector salud en la sociedad Brasileña actual, en el cual desarrollan las acciones de salud y luego presentan el grupo de estudio en cuestión. A continuación desarrollan el referencial teórico y metodológico, definiendo las categorías analíticas, politica y políticas sociales, organización tecnológica del trabajo, servivicios de salud, niño y familia. Al finalizar presentan una síntesis de resultados de algunas investigaciones concluidas en los últimos años (1995 a 1997).

TÉRMINOS CLAVES: asistencia integral al niño y al adolescente, enfermería pediátrica, enfermería neonatal

\section{REFERÊNCIAS BIBLIOGRÁFICAS}

01. BECKER, H.S. Métodos de pesquisa em ciências sociais. Trad. Marco Estevão e Renato Aguiar. São Paulo: Hucitec, 1994.

02. CANO, M.A.T.; FERRIANI, M.G.C.; ROCHA, S.M.M.; UBEDA, E.M.L. Instituições que prestam assistência aos adolescentes em Ribeirão Preto. Rev. Bras. Sexual. Humana, v.7, p.224237, 1996. n. especial.

03. CARAPINHEIRO, G. Saberes e poderes no hospital: uma sociologia dos serviços hospitalares. Porto: Afrontamento, 1993.

04. COLLET, N. Transformações no ensino das técnicas em enfermagem pediátrica. Ribeirão Preto, 1995. 195p. Dissertação (Mestrado) Escola de Enfermagem de Ribeirão Preto, Universidade de São Paulo.

05. COLLET, N.; ROCHA, S.M.M. Transformações no ensino das técnicas em enfermagem pediátrica. Goiânia: AB, 1996.
06. DELGADO, J.M.R. Free behaviour and brain stimulation. In: PFEIFFER, C.C.; SMYTHIES, J.R. (eds.). International review of neurobiology. 6.ed. New York: Academic, 1964.

07. FERRO, M.A.R.; PEREIRA, E.B.; SCOCHI, C.G.S. Avaliação do sistema de nascidos vivos no município de Ribeirão Preto. In: CONGRESSO BRASILEIRO DE SAÚDE COLETIVA, 5., Águas de Lindóia, 25 a 29 de agosto, 1997. p.221.

08. FRANÇANI, G.M.; ZILIOLI, D.; SILVA, P.R.F.; SANT'ANA, R.P.M.; LIMA, R.A.G. Prescrição do dia: infusão de alegria. Utilizando a arte como instrumento na assistência à criança hospitalizada. In: CONGRESSO BRASILEIRO DE ENFERMAGEM, 48., São Paulo/SP, outubro 1996. Programa e resumos. São Paulo: Associação Brasileira de Enfermagem, 1996. p.201. 
09. FUNDAÇÃO INSTITUTO BRASILEIRO DE GEOGRAFIA E ESTATÍSTICA/FIBGE. Crianças e adolescentes: indicadores sociais. Rio de Janeiro: IBGE-Departamento de Estatísticas e Indicadores Sociais, 1994. v.1, edição especial.

10. HUTT, S.J.; HUTT, C. Observação direta e medida do comportamento. São Paulo: EPU, 1974.279p.

11. IMORI, M.C.; ROCHA, S.M.M.; SOUZA, H.G.B.L.; LIMA, R.A.G. Assistência à criança hospitalizada: benefícios e obstáculos a participação dos pais. In: CONGRESSO PAULISTA DE ENFERMAGEM PEDIÁTRICA, 1, Anais. São Paulo, 1995. p.18.

12. KAMADA, I.; ROCHA, S.M.M. Assistência de enfermagem em unidade de internação neonatal: medidas para prevenção de infecções hospitalares. Rev. latino-am.enfermagem, Ribeirão Preto, v.5, n.1, p.37-48, jan. 1997.

13. LAURENTI, R. et al. Estatística de saúde. São Paulo: EPU, 1987.

14. LIMA, R.A.G. A enfermagem na assistência à criança com câncer. Goiânia: AB, 1995.

15. C C C C C C C construçãão da assistência integral. Ribeirão Preto, 1996. 258p. Tese (Doutorado) - Escola de Enfermagem de Ribeirão Preto, Universidade de São Paulo.

16. LIMA, R.A.G.; ROCHA, S.M.M.; SCOCHI, C.G.S. Asistencia al niño hospitalizado en el Brasil: reflecciones acerca de la participación de los padres. In: CONFERENCIA DE ENFERMERIA FAMILIAR, 4., Valdívia / Chile, 1997.

17. LIMA, R.A.G.; PAMPLONA, V.L.; MENOSSI, M.J. A situação do leito hospitalar para crianças em Ribeirão Preto. Rev. Paul. Hosp., v.41, n.1, p.16-21, jan./dez. 1994.

18. LÜDKE, M.; ANDRÉ, M.E.D.A. Pesquisa em educação: abordagens qualitativas. São Paulo: EPU, 1986. 99p.

19. MaC GRATH, P.J. et al. Report of the subcommithes on assent and methodologic issues in the management of pain in childhod cancer. Pediatrics. USA, n.5, p.814-817, nov. 1990.

20. MARQUES, M.B. Contribuição ao estudo do movimento internacional de proteção à maternidade e a infância. $150 \mathrm{p} . \mathrm{s} / \mathrm{d}$. / mimeografado/

21. MELLO, D.F.; FERRIANi, M.G.C. Estudo exploratório de opiniões de mães sobre a saúde das crianças menores de 5 anos. Rev. latinoam. enfermagem, v.4, n.2, p.87-100, 1996.
22. MELLO, D.F.; JAVORSKY, M.; SCOCHI, C.G.S.; FELICIANO, R.A.F. Disponibilidade de leitos neonatais na rede hospitalar de Ribeirão Preto/ SP. In: CONGRESSO PAULISTA DE ENFERMAGEM PEDIÁTRICA. 1. Anais. São Paulo, 1995. p. 34.

23. MENDES, E.V. (org.) Distrito sanitário. São Paulo: HUCITEC/ABRASCO, 1994. 310p.

24. MENDES GONÇALVES, R.B. Tecnologia social das práticas de saúde: características tecnológicas do processo de trabalho na Rede Estadual de Centros de Saúde de São Paulo. São Paulo: HUCITEC/ABRASCO, 1994.

25. MENDRAS, H. Princípios de sociologia. Rio de Janeiro: Zahar, 1975.

26. MINAYO, M.C.S. O desafio do conhecimento: pesquisa qualitativa em saúde. Rio de Janeiro: HUCITEC/ABRASCO, 1993.

27. MISHIMA, F.C.; SCOCHI, C.G.S.; FERRO, M.A.R.; LIMA, R.A.G. Declaração de nascidos vivos: análise do seu preenchimento no município de Ribeirão Preto/SP. In: CONGRESSO BRASILEIRO DE SAÚDE COLETIVA, 5., Águas de Lindóia/SP, 25 a 29 de agosto de 1997, p.341.

28. PATTON, M.Q. Qualitative evaluation. Beverly Hills, Ca.: SAGE, 1980.

29. RIBEIRÃO PRETO. Programa de coleta e análise de estatísticas vitais. Ribeirão Preto: Secretaria Municipal da Saúde, Departamento de Informática (SICAEV), 1995.

30. ROCHA, S.M.M. A criança na sociedade brasileira: educar, prevenir, cuidar. In: CONGRESSO PAULISTA DE ENFERMAGEM PEDIÁTRICA.1. Anais. São Paulo, 1995. p.37.

31. ROCHA, S.M.M.; SCOCHI, C.G.S.; SOUZA, H.G.B.L.; Características tecnológicas do processo de trabalho em berçários. In: CONGRESSO BRASILEIRO DE PERINATOLOGIA, 15., Belo Horizonte, 1996. Anais. Belo Horizonte: Sociedade Brasileira de Pediatria, 1996. p.96.

32. ROCHA, S.M.M., LIMA, R.A.G.; SCOCHI, C.G.S. Assistência integral à saúde da criança no Brasil: o ensino e a prática de enfermagem pediátrica. Saúde e Sociedade, São Paulo, 1997. /no prelo/ 33. SANT'ANNA, S.C. A suplementação alimentar nas unidades básicas de saúde do município de Ribeirão Preto. Ribeirão Preto, 1995. 105p. Dissertação (Mestrado) - Escola de Enfermagem de Ribeirão Preto, Universidade de São Paulo.

34. SANTOS, W.G. Cidadania e justiça. Rio de Janeiro: Campus, 1979. 
35. SARTI, C.A. Aspectos antropológicos e sociais da família. In: CONGRESSO PAULISTA DE ENFERMAGEM PEDIÁTRICA, 1., São Paulo, 1995. Anais. São Paulo: Universidade Federal de São Paulo/Escola de Enfermagem da Universidade de São Paulo/Faculdade de Enfermagem do Hospital Israelita Albert Einstein, 1995. p.9.

36. SCOCHI, C.G.S.; MELLO, D.F.; JAVORSKI, M.; MENOSSI, M.J. O alojamento conjunto em hospitais-maternidade de Ribeirão Preto: análise da assistência. Acta Paul. Enf., v.9, n.3, 1996a.

37. SCOCHI, C.G.S.; COSTA, I.A.R.; ARRUDA,N.M. Evolução histórica da assistência ao recémnascido: um panorama geral. Acta Paul. Enf., 1996b./no prelo/

38. SCOCHI, C.G.S.; ANGERAMI, E.L.S.; ROCHA, S.M.M.; LIMA, R.A.G. A organização do trabalho na assistência ao recém-nascido em berçários da regional de Ribeirão Preto/SP. Brasil - 1992. Rev. latino-am. enfermagem, Ribeirão Preto, v.5, n.1, p.27-36, jan. 1997a.
39. SCOCHI, C.G.S.; COSTA, I.A.R.; ROCHA, S.M.M.; PRATALI, M.T.R.; SILVA NETTO, K.A. Intervalo entre o nascimento e o registro civil: situação do município de Ribeirão Preto. In: CONGRESSO BRASILEIRO DE SAÚDE COLETIVA, 5. Águas de Lindóia/SP, 25 a 29 de agosto, 1997b. p.93-4.

40. SILVA, M.H.A.; RIUL, M.J.S.; ROSSANEZ, L.S.; SCOCHI, C.G.S. A assistência aos pais de crianças de alto risco em unidade de terapia intensiva neonatal: experiência do Hospital das Clínicas de Ribeirão Preto. In: CONGRESSO BRASILEIRO DE PERINATOLOGIA, 15., Belo Horizonte, 1996. Anais. Belo Horizonte: Sociedade Brasileira de Pediatria, 1996. p.96.

41. TESTA, M. Pensar em saúde. Porto Alegre: Artes Médicas, 1992.226p.

42. TORRITESI, P.; VENDRÚSCULO, D.M.S. A dor na criança com câncer: modelos de avaliação. Rev. latino-am. enfermagem, 1997./no prelo/

43. WEICK, K.E. Systematic observational methods. In: LINDZEY, G.; ELLIOT, A. The handbook of social psichology. 2. ed. Massachussets: Addison - Wesley, 1968. p.357-366. 